\title{
Mutualidades do desejo: Sexo, Religião e Intermedialidade em Corpo Verde, de Maria Velho da Costa e Júlio Pomar
}

\section{Daniel Floquet \\ Universidade do Porto}

\begin{abstract}
Resumo: Publicada em 1979, a obra Corpo Verde é formada por 23 versos de Maria Velho da Costa e 8 desenhos de Júlio Pomar. Neste ensaio, observo de que forma verbo e imagem combinam-se a fim de criar um único objeto estético, dedicado ao tema da experiência sexual. A análise destaca como os dois artistas subvertem pressupostos hierárquicos relacionados a dicotomias como masculino/feminino e atividade/passividade, bem como material/espiritual, visto o forte diálogo que realizam com o livro bíblico $O$ Cântico dos Cânticos. Além disso, aborda-se a problemática do chamado olhar masculino, conforme
\end{abstract} desenvolvida pelo campo de estudos da intermedialidade.

Palavras-chave: intermedialidade, écriture féminine, experiência sexual, Maria Velho da Costa, Júlio Pomar

\begin{abstract}
Published in 1979, Corpo Verde is composed of 23 verses by Maria Velho da Costa and 8 drawings by Julio Pomar. In this essay, I try to analyze how words and images combine themselves in order to create a single aesthetic object, focused on the theme of sexual experience. The analysis highlights how both artists subvert the hierarchies related to the dichotomies of masculine/feminine and active/passive, as well as with the material/spiritual, based on the strong dialogue they make with the biblical book of Songs of Solomon. Beyond that, this essay focus on the so-called male gaze, as developed by the intermediality studies.
\end{abstract}

Keywords: intermediality, écriture féminine, sexual experience, Maria Velho da Costa, Júlio Pomar 
A intermedialidade, especialmente quando associada à ideia de coautoria, não é fenômeno incomum à obra de Maria Velho da Costa. De fato, nos últimos 25 anos, a autora portuguesa esteve envolvida na elaboração de diversas obras a que se pode atribuir a denominação de intermediais, como é o caso de Das Áfricas, misto de ensaio fotográfico e texto literário que publicou ao lado do fotógrafo José Afonso Furtado. No campo audiovisual, assinou diversos roteiros - muitos escritos em parceria - para o cinema, ${ }^{1}$ medium intermedial por excelência, além de escrever a peça de teatro Madame, ${ }^{2}$ dirigida por Ricardo Pais.

Apesar da frequência com que surgem no percurso artístico da autora, suas obras intermediais permanecem pouco estudadas. 0 presente ensaio busca colaborar neste campo ao centrar-se na análise de Corpo Verde, obra publicada em 1979 em colaboração com o pintor português Júlio Pomar, composta por 23 pequenos versos de Velho da Costa e 8 desenhos do artista plástico português. Trata-se da primeira incursão genuinamente intermedial da autora. ${ }^{3}$

Já Pomar, no período da publicação desta obra, não era estranho ao diálogo intermedial. Ao longo de sua carreira, o pintor português utilizou diversas vezes as literaturas portuguesa e internacional como tema e inspiração para suas pinturas, como o emblemático quadro Tigre, de 1978, inspirado nas impressões de Pomar ao ler, em francês, o texto "Rose et Bleu", do escritor argentino Jorge Luís Borges. Pomar também criaria inúmeras ilustrações que acompanhariam edições de diversas obras consagradas, para autores tão variados como Miguel de Cervantes e Camilo Castelo Branco. No entanto, seja nas pinturas, seja nas ilustrações, a tendência parece ser tomar textos prévios como temas que serão transpostos para o universo pictórico. A parceria com Velho da Costa aqui em estudo não se enquadra nessa situação, como se demonstrará a seguir.

Em Corpo Verde, verbo e imagem combinam-se em torno de um tema explorado anteriormente pelos dois autores: a experiência sexual. A aproximação dos dois media contribui para a criação de um objeto artístico erótico, estimulando de forma complementar a imaginação do leitor e sua reflexão sobre o tema da sexualidade. Em outras palavras, os textos de Velho da Costa e os desenhos de Pomar, ocupando páginas opostas na 
encadernação da obra, mantêm sua independência formal ao mesmo tempo que reforçam entre si pressupostos em comum acerca do referido tema. Pode-se classificar tal relação de acordo com o que Irina Rajewsky denominou combinação medial (media combination):

The intermedial quality of this category is determined by the medial constellation constituting a given media product, which is to say the result or the very process of combining at least two conventionally distinct media or medial forms of articulation. These two media or medial forms of articulation are each present in their own materiality and contribute to the constitution and signification of the entire product in their own specific way. (Rajewski 2005: 51-52)

[0 caráter intermedial desta categoria é determinado pela constelação medial que constitui um determinado produto, ou seja, o resultado de combinar pelo menos dois media convencionalmente diferentes. Estes dois media estão ambos presentes na sua própria materialidade e contribuem, cada um a seu modo, para a constituição e significação de todo o produto].4

O presente ensaio busca elucidar não apenas o papel dessa complementaridade na construção da obra, mas também entender o modo como Velho da Costa e Pomar redimensionam o papel majoritariamente secundário e passivo ao qual a figura feminina é tradicionalmente relegada no campo da experiência sexual. No entanto, afirmar que a leitura de Corpo Verde é intermedial não deve nublar a percepção de que Costa e Pomar apresentam algumas estratégias enunciativas distintas, que podem se beneficiar de uma análise separada em um primeiro momento, para em seguida contrastarmos as duas faces da obra de forma pormenorizada.

\section{1. "nas colunas das tuas coxas": Sexo e religião em Corpo Verde}

A leitura crítica de Corpo Verde se beneficiará ao reconhecer o modo como a obra dialoga com uma terceira voz presente em suas páginas: os versos do livro bíblico $O$ Cântico dos Cânticos, também traduzido como Cantares de Salomão. A epígrafe de Corpo Verde apresenta ao leitor uma citação extraída deste livro bíblico: "Que a sua mão esquerda esteja sob a minha cabeça e que a sua direita me abrace"(apud Costa/Pomar 1979: 7). Trata-se de uma passagem repetida duas vezes no Cântico - nomeadamente no canto 2, versículo 6, e 
no canto 8, versículo 3. Nas duas ocorrências, o verso é enunciado por uma figura feminina, central em sua arquitetura narrativa, pois esse conjunto de poemas é construído por meio de diálogos entre ela e uma voz masculina, seu noivo, com interdições pontuais de um coro de vozes, nomeado como "filhas de Jerusalém".

Porém, o Cântico dos Cânticos não ocupa apenas posição de epígrafe em Corpo Verde, mas atua também como elemento estruturante - formal e tematicamente. É através desse diálogo que os versos de Velho da Costa subvertem, por meio da força criativa da linguagem, as estruturas patriarcais que marginalizam o papel feminino no espaço da experiência sexual. Além disso, deve-se também ressaltar que a escolha desta epígrafe reflete uma questão histórica: o livro bíblico está envolvido em um debate milenar a respeito da recorrente sugestão erótica de seus versos. Com efeito, ele seria incluído no cânon da Bíblia judaica apenas no século I d.C., sob duas justificativas: primeiro, de que seria Salomão o autor de seus versos - fato hoje universalmente questionado; segundo, de que o erotismo presente no texto seria indício alegórico: não se trataria, portanto, do amor terreno entre um homem e uma mulher, mas da união simbólica entre Deus e Israel. A tradição católica seguiria a interpretação judaica, mas entendendo tratar-se da união entre Deus e a Igreja.

Tal leitura encontraria resistência mesmo no seio do catolicismo: Teodoro de Mopsuéstia recuperaria a interpretação erótica do Cântico no século V, entendendo-o como poema nupcial, celebrando o casamento entre Salomão e a filha do faraó, interpretação rejeitada pela Igreja no V Concílio Ecumênico, em 553, onde se reafirmaria a dimensão alegórica do texto. Assim, são numerosas as reflexões sobre este livro bíblico, mas parecem organizar-se em torno destas duas interpretações principais: a que o entende como leitura alegórica e a que aborda as imagens presentes no texto em sua materialidade, atribuindolhe por isso forte dimensão erótica.

Evidentemente, o Cântico não é o objeto principal deste ensaio. Sua função aqui deve ser dimensionada no sentido em que auxilia a leitura de Corpo Verde, sendo bastante seguro afirmar que os versos de Velho da Costa inclinam-se para a interpretação erótica dos 
Cantares de Salomão. 0 texto bíblico, diretamente mencionado apenas no início, atravessará os versos da autora portuguesa como filigrana.

Inicialmente, pode-se apontar o fato de que os versos de Corpo Verde emulam a já mencionada estrutura dialogal do Cântico. No texto bíblico, lê-se: "Os teus lábios destilam doçura, ó minha noiva; há mel e leite sob a tua língua, e o aroma dos teus vestidos é como o aroma do Líbano"5 (Cântico 4: 11; negritos meus). O uso dos pronomes demarca a proximidade das vozes: quando um dos membros do casal enuncia seu texto, dirige-se predominantemente ao parceiro de forma direta, como quem sabe que está a ser ouvido. Nos versos de Corpo Verde, encontra-se a mesma estrutura: "Debati-me diante da tua face como a fêmea do açor no seu primeiro cobrimento. Mas a tua saliva vestiu-me de branco o dentro do corpo." (Costa/Pomar 1979: 11; negritos meus) .

0 contraste sistemático entre as duas obras revela semelhanças maiores do que a perceptível intimidade entre as vozes participantes. Além desse aspecto, tanto no polêmico livro bíblico como na obra portuguesa as imagens poéticas direcionam-se à descrição do próprio corpo e do corpo do parceiro. No Cântico, a voz masculina enuncia assim o corpo feminino: "Os teus dois seios são dois filhotes gémeos de uma gazela que se apascentam entre os lírios" (Cântico 4: 5). No Corpo Verde, a erotização também está presente no modo como a voz feminina descreve o corpo do companheiro masculino: "Moro no teu torso, perfume e falas. Conheço a tua língua e o teu vagir-me nas entranhas como uma cidade contínua" (Costa/Pomar 1979: 37).

Tal espelhamento torna-se ainda mais relevante quando se evidencia que as imagens de Velho da Costa parecem ecoar diversas outras já fornecidas pelo Cântico. Em ambos os textos, o corpo humano é comparado a signos que evocam a natureza, como "rebanho", "lírio", "jardim", "horta", ou construções religiosas, como "templos" e "colunas". Além disso, demarcam-se linguisticamente a "língua", os "peitos", o "ventre”, o "umbigo", as "coxas". Os amantes, em ambos os textos, chamam-se de irmãos:

Quem dera fosses meu irmão, amamentado aos seios da minha mãe! Ao encontrar-te na rua beijar-te-ia, sem censura de ninguém. (Cântico 8: 1) 
Que o meu irmão me beije e se beije no meu beiço como se fôramos a

Flor de outra justiça. (Costa/Pomar 1979: 40)

A autora portuguesa, contudo, fornece às imagens dimensão erótica ainda mais explícita. Se, no poema bíblico, passagens como "o seu fruto é doce na minha boca" (Cântico 2: 3) e "meu amado passou a sua mão pela fresta e as minhas entranhas estremeceram por ele" (idem: 5: 4) permanecem entendidas pela liturgia religiosa como alegorias exclusivamente espirituais, na leitura de Velho da Costa não há dúvida a que o texto se refere quando se lê "No negrume da tua testa no sono provei com a minha boca a maciez do lírio e no cingir-te com a minha vulva o silêncio do toiro sob as gotas da noite"6 (Costa/Pomar 1979: 15; negritos meus).

É notório que apenas em Velho da Costa seria possível encontrar um vocabulário como "vulva", mas essa mesma passagem parece remeter o leitor de volta ao Cântico, onde se lê "(...) tenho a cabeça coberta de orvalhos/ e os meus cabelos, das gotas da noite" (Cântico 5: 2; Negritos meus). A comunicação entre os dois textos parece constantemente seguir essa ordem circular: imagens do Cântico retornam em Corpo Verde como descrições assumidamente de carácter sexual:

O teu umbigo é taça redonda. Que não falte vinho doce! 0 teu ventre é monte de trigo, todo cercado de lírios. (Cântico 7:3)

O sol do teu umbigo, úbere das tuas mães, não resplandece mais que esse membro que entre ti e mim nos convoca e contempla. (Costa/Pomar 1979: 31)

Entretanto, em meio ao recorrente diálogo paródico acima detalhado, não se pode ignorar uma importante diferença: Corpo Verde emula o carácter dialogal do Cântico de forma significativamente recortada, pois os 23 versos de Velho da Costa são todos enunciados apenas pela voz feminina, dirigindo-se a um companheiro.

Ao elidir a voz masculina do discurso e construir um texto que se organiza em torno de uma voz feminina que celebra a experiência do sexo, descrevendo-a, por meio da linguagem poética, apenas nos termos do prazer resultante dessa experiência, o texto de 
Velho da Costa colore-se de forte questionamento social. Afinal, Simone de Beauvoir, em sua obra O Segundo Sexo, já criticava a assimetria de tratamento concedida a homens e mulheres nesse tema:

A civilização patriarcal votou a mulher à castidade; reconhece-se mais ou menos abertamente ao homem o direito à satisfação dos seus desejos sexuais, ao passo que a mulher é confinada ao casamento: para ela, o acto carnal, não sendo santificad o pelo código, pelo sacramento, é falta, queda, derrota, fraqueza; tem o dever de defender sua virtude, a honra; se "cede", se "cai", suscita o desprezo; ao passo que até na censura que se inflige ao seu vencedor há admiração. (Beauvoir 2008: 128)

Dessa forma, por ser exigido da mulher constante vigilância de seus próprios atos, ela experiencia o espaço ao seu redor de modo distinto ao do homem. Constantemente observada, passa a observar a si mesma. John Berger, na obra Ways of Seeing, entenderia que essa dupla vigilância - a da sociedade sobre a mulher e a da mulher sobre si mesma condicionaria fortemente o comportamento feminino na esfera social:

She has to survey everything she is and everything she does because how she appears to others, and ultimately how she appears to men, is of crucial importance for what normally thought of as the success of her life. Her own sense of being in herself is supplanted by a sense of being appreciated as herself by another. (Berger 1972: 47)

[A mulher deve analisar tudo o que é e tudo aquilo que faz porque a maneira como se apresenta aos outros e, em última instância, a maneira como se apresenta aos homens é de extrema importância para aquilo que é habitualmente considerado como sucesso na sua vida. Seu próprio sentimento de ser ela mesma é suplantado pelo sentimento de ser apreciada como tal pelos outros].

Contudo, Simone de Beauvoir iria além ao perceber que o patriarcalismo não ocorre apenas por meio de imposições na conduta social; o domínio da linguagem também reforça culturalmente uma posição de inferioridade da condição feminina; não apenas na relação em sociedade, mas também durante a realização do ato sexual:

Os gregos chamavam parthenos ademos (virgem insubmissa) à mulher que não conhecera macho. 
Os romanos qualificavam Messalina de "invicta", porque nenhum dos amantes lhe dera prazer. (...) 0 vocabulário dos homens inspira-se no vocabulário militar: o amante tem o ímpeto do soldado, o sexo retesa-se como um arco, quando ejacula "descarrega" (...); fala de ataque, de assalto, de vitória. Há no acto sexual um sabor de heroísmo. (Beauvoir 2008: 128)

Mesmo quando não enquadrada na metaforização estritamente militar, a linguagem ainda reforça a hierarquização das relações sexuais. Beauvoir relembra que, culturalmente, à mulher são associadas qualidades apenas "passivas", como ser "quente" ou "fria" (idem: 130); diz-se que o homem "toma o seu prazer", enquanto a mulher "dá esse prazer" (idem: 141). Os corpos de ambos os sexos estão, assim, imbuídos “de representações colectivas que dão ao acto masculino um carácter glorioso e que fazem da perturbação feminina uma abdicação vergonhosa" (ibidem; itálicos da autora).

Em Corpo Verde, os versos de Velho da Costa incorporam alguns dessas representações culturais, mas, em regra geral, a autora descreve-os de forma subversiva:

Comovem-me os teus quadris de guerreiro virgem. E as tuas mãos

estão na minha garganta como um colar de opala e âmbar, os teus

tornozelos enlaçados nos meus são como as asas da borboleta nocturna

e os guizos da dança. (Costa/Pomar 1979: 28)

No exemplo acima, a voz feminina entrega-se, mas a linguagem empregada mostra ao leitor que há também domínio nesta entrega. Se o companheiro masculino é ainda um "guerreiro", seu status de conquistador é rebaixado a sua condição de "virgem", e suas mãos na garganta, antes de uma ilusória indicação de posse, assumem, durante a união sexual, o papel de ornamentos de beleza.

Um processo semelhante, e igualmente significativo, pode ser encontrado quando o órgão sexual masculino é descrito como um "lírio" (idem: 15). Na simbologia cristã, trata-se de um símbolo primordialmente feminino, associado à pureza e à inocência e muitas vezes equiparado à Virgem Maria (Chevalier/Gheerbrant 1994: 413); no Cântico, o lírio é também comparado à mulher amada: "Tal como um lírio entre os cardos/é minha amada entre as jovens"7 (Cântico 2: 2). Dessa forma, ao comparar o falo do parceiro a um símbolo feminino 
e, por meio do paladar, destacar a sua "maciez" (idem: 15), os versos de Velho da Costa conferem ao corpo masculino qualidades bem distantes das metáforas militares analisadas por Beauvoir.

Essa subversão das hierarquias associadas ao binômio masculino/feminino pode ser entendida à luz das estratégias da corrente feminista francesa conhecida como écriture féminine. Apoiando-se no conceito de differánce proposto por Derrida, estudiosas como Hélène Cixous e Luce Irigaray defendem que a própria ascensão dos pressupostos patriarcais ocorre por meio da repressão de aspectos culturalmente entendidos como femininos. Conforme observa a filósofa Arleen Dallery:

The preconditions for the production of western knowledge, its standards of objectivity, rationality, and universality, require the exclusion of the feminine, the bodily, the unconscious. Indeed, the logical ordering of reality into hierarchies, dualism, and binary systems presupposes a prior gender dichotomy of man/woman. Not only has women's voice or experience been excluded from the subject matter of western knowledge, but even when the discourse is "about" women, or women are the speaking subjects, (it) they still speak (s) according to phallocentric codes. (Dallery 1989: 53)

[Os pré-requisitos para a produção do conhecimento ocidental, as suas normas de objetividade, racionalidade e universalidade, implicam a exclusão do feminino, do corporal, do inconsciente. De fato, a organização lógica da realidade em hierarquias, em dualismos e em sistemas binários pressupõe uma dicotomia de gênero prévia entre homem/mulher. Não apenas a voz e a experiência da mulher foram excluídas das temáticas do conhecimento ocidental, mas mesmo quando o discurso é "sobre" mulheres ou quando as mulheres ocupam o lugar da enunciação, continuam a expressar-se de acordo com códigos falocêntricos].

Tais conflitos de poder afetam o modo como a mulher experiencia o próprio corpo, questão que assume importância fulcral nos estudos dessa corrente:

The structures of language and other signifying practices that code woman's body are equally oppressive as the material/social structures that have tended to mediate one's awareness of one's body and self and erotic possibilities. (idem: 54 )

[As estruturas da língua e outras práticas de significação que codificam o corpo da mulher são tão 
opressivas quanto as estruturas materiais/sociais que tendem a mediar a consciência que o indivíduo tem do seu corpo, de si mesmo e de suas possibilidades eróticas].

Para a écriture féminine, "a hegemonia do patriarcado está incorporada na linguagem" (idem: 62). Se o corpo feminino é também texto (idem: 54), apenas na arena da linguagem pode-se subverter os pressupostos patriarcais que o enquadram (idem: 58). Por isso, a literatura assume, sob a ótica da écriture féminine, um importante papel social, pois a escrita literária potencializaria a liberdade de expressão feminina em um mundo onde predominam símbolos repressores.

Em Corpo Verde, a voz feminina busca o direito de descrever-se em seus próprios termos: "Porque onde tu dizes pátria e ovo eu digo a toda terra erecta do teu falo, canoa e horto. E onde não falamos a fricção da nossa pele gera mais sóis" (Costa/Pomar 1979: 17). Em busca de um vocabulário autônomo, o eu-lírico não será mais "pátria e ovo", denominações dadas pelo outro, mas "canoa" e "horto", palavras escolhidas por ela própria para descrever seu corpo, reconquistado por meio da linguagem. ${ }^{8}$ Porém, não se deseja também simples reversão hierárquica: a fricção da pele, o contato - social e sexual - ao gerar "sóis", é entendido como produtivo, rico de possibilidades e mutualmente benéfico: "Agarra o meu cabelo que eu te arredondo o mundo e me concitas pela tua mão aos outros continentes, mares irmãos" (idem: 18).

É válido observar que a fluidez entre o masculino e o feminino também é encontrada no Cântico dos Cânticos, o que apenas reforça a aproximação com Corpo Verde que vem aqui sendo explorada. 0 texto bíblico, como se sabe, não traz demarcadas as falas da noiva e do noivo, ou mesmo as da breve participação do coro das "filhas de Jerusalém". Algumas traduções bíblicas procuram resolver essa questão inserindo sinais como "Ele" e "Ela" antes dos versos, mas, como bem observa a edição da Nova Bíblia dos Capuchinhos, essa decisão visa apenas "maior facilidade de leitura", reconhecendo que a "atribuição a cada uma das duas principais personagens se torna difícil de fazer" (1998: 1050). Com efeito, há passagens do Cântico fronteiriças entre o discurso das personagens feminina e masculina em que não é possível afirmar com segurança quem de fato é seu enunciador. 
Vale também notar que a fluidez no Cântico ocorre de outro modo: as mesmas imagens poéticas ora são pronunciadas pela voz feminina, ora pela voz masculina. A passagem "os teus olhos são como os das pombas" é enunciada pela voz masculina no Canto 1 e pela voz feminina no Canto 5. A comparação de que "melhor é o teu amor do que o vinho" segue a mesma lógica, ao ser enunciada pela voz feminina no Canto 1 e pela voz masculina no Canto 4.

Dessa forma, Corpo Verde incorpora o Cântico de modo a apontar que o discurso religioso, um dos mais importantes articuladores do discurso patriarcal, traz dentro de si contradições internas: a Bíblia, em muitas passagens, reafirma a condição submissa da mulher e reduz o ato sexual exclusivamente em razão da procriação. Porém, traz em suas páginas um texto facilmente identificado como erótico, em que masculino e feminino são fluidos, em que ambos são enunciadores do discurso, ${ }^{9}$ em que o corpo é celebrado em sua condição terrena, apesar do esforço da Igreja em afirmar o contrário. Como observaria Agustina Bessa-Luís:

A Igreja tem tido um enorme empenho em qualificar o Cântico dos Cânticos como uma obra de inspiração mística. Contudo, a história bíblica e um simples olhar sobre a natureza humana dizem-nos muito do carácter profano desse poema lírico. (Bessa-Luís 2001: 6)

Frederico Lourenço também rejeita a interpretação alegórica do Cântico, classificando-o como o "brinde-surpresa da Bíblia", "uma pequena antologia de versos eróticos de que Jeová está totalmente ausente" (Lourenço 2015: 85). Por meio do recurso do humor, o autor conclui sua posição:

É melhor dizermo-nos que os peitos referidos (8:10) não são peitos, mas símbolos de realidades místico-divinas. Contudo, temos o direito de ser selectivos com a aplicação destas leituras alegóricas, pois por vezes é mais aconselhável ler o texto à letra! É claro que o noivo a entrar no "seu jardim" para "colher lírios" no "canteiro dos aromas" (6:2) só designa mesmo atividades hortícolas... (idem: 87)

Corpo Verde, no entanto, não está em completo acordo nem mesmo com as críticas 
acima formuladas por Agustina e Lourenço, pois os versos de Velho da Costa questionam a própria oposição entre carne e espírito: "O teu rosto sobre o meu rosto na obscuridade rasga estes véus entre a matéria e o ânimo" (Costa/Pomar 1979: 34; negritos meus). 0 ato sexual é assim poeticamente descrito como capaz de romper o espaço-tempo: "Como uma estátua equestre no vácuo, em pura prata estelar, nos montamos" (Costa/Pomar 1979: $32)$.

Essa dimensão metafísica é auxiliada pela constante associação do corpo a elementos religiosos, recurso também encontrado no Cantares de Salomão:

Vestida de teu suor fui sobranceira ao medo. Mas todos os templos batidos pelos ares estão nas colunas das tuas coxas. Venerado o teu septo nasal e a pele do teu crâneo como se foram da criança própria surge o susto - todo o amor é abolição de limites até do próprio corpo. (idem: 22; negritos meus)

Ao dar dimensão sagrada ao corpo, ao descrevê-lo como veículo para um entendimento maior de si e do mundo, Corpo Verde veste-se não apenas de forte conotação herética, mas reafirma também o ato sexual como redentor das hierarquias de gênero, visto que a obra celebra sua união. Não há em seus versos domínio de um aspecto sobre o outro, mas constante troca e crescimento. Como se lê no próprio texto, a união dos corpos é “a flor de outra justiça" (idem: 40).

\section{2. "Mares irmãos": Para uma leitura intermedial de Corpo Verde}

Em What Do Pictures Want?, W. J. Mitchell afirma que as imagens comumente assumem uma posição culturalmente associada ao feminino, ou seja, são signos silenciosos, representações a que foram negadas a construção de um discurso autônomo (Mitchell 2005: 29). Seu papel é despertar o desejo do observador, sem nunca escapar de sua condição de passividade, sempre dependente de um olhar ativo para lhe atribuir significado (idem: 44). Mitchell não se refere, ao formular essa comparação, à imagem de mulheres, mas à ideia mais ampla da imagem como uma mulher, ao mesmo tempo que o portador do olhar, 
dono também do discurso que atribuirá significado à imagem, seria, portanto, representado simbolicamente pelos homens (idem: 35 ).

A divisão acima proposta por Mitchell fundamenta-se em bases históricas. Conforme observa Simon Goldhill, embora a diferenciação entre um "olhar masculino" (male gaze) e um “olhar feminino" (female gaze), em termos de pressupostos formais, seja assunto de forte polêmica no campo dos estudos de gênero (gender studies), a divisão social da prática do olhar é confirmada por diversas fontes:

There can be no doubt that institutionally the practice of viewing was gendered: men could look at the Secret Museum of Pompeii, for example, but women (and children) were not allowed to visit lest they be corrupted by such sights. Similarly, there was a long-running argument about the presence of women at life classes as artists, and about the morality of life classes per se, and the subsequent display of images of nude women. The flâneur was a man. (Goldhill 2007: 8)

[Não há dúvida de que, institucionalmente, a prática do olhar era condicionada por questões de gênero: os homens podiam observar o Museu Secreto de Pompeii, por exemplo, mas as mulheres (e as crianças) estavam proibidas de o visitar, sob o risco de serem corrompidas por tais vi sões. Da mesma forma, perdurava uma discussão antiga sobre a presença das mulheres em aulas com modelo vivo na qualidade de artistas, bem como sobre a moralidade dessas aulas e sobre a subsequente apresentação de imagens de mulheres nuas. 0 flâneur era um homem].

Ao propor uma leitura de Corpo Verde a partir de uma perspectiva intermedial, percebe-se que a obra de Velho da Costa e Pomar confronta-se com algumas das questões levantadas acima: o olhar não apenas é representado por um eu-lírico assumidamente feminino, mas essa voz ${ }^{10}$ convoca o corpo masculino como objeto deste olhar. Ao transladar o homem de seu costumeiro papel de observador para o papel de observado, os versos de Corpo Verde confrontam-se com uma vasta tradição ainda hoje reproduzida por meio de discursos, imagens, quadros, músicas (Dimen 1989: 41), e tal gesto torna-se ainda mais subversivo por inserir essa mudança de eixo em um contexto de erotismo. Afinal, como observa Laura Mulvey em seu célebre ensaio "Visual Pleasure and Narrative Cinema",

In a world ordered by sexual imbalance, pleasure in looking has been split between active/male and 
passive/female. The determining male gaze projects its phantasy on to the female form which is styled accordingly. In their traditional exhibitionist role women are simultaneously looked at and displayed, with their appearance coded for strong visual and erotic impact so that they can be said to connote to-be-looked-at-ness. (Mulvey 1975: 8)

[Em um mundo organizado em função do desequilíbrio sexual, o prazer de olhar é dividido em ativo/masculino e passivo/feminino. 0 determinante olhar masculino projeta a sua fantasia para a forma feminina, a qual é estilizada em conformidade. No seu papel tradicional de exibicionistas, as mulheres são simultaneamente observadas e expostas, sendo a sua aparência codificada para um elevado impacto visual e erótico, permitindo conotá-las com o "ser observado"].

Por a dicotomia atividade/passividade ser condicionada por meio da dicotomia masculino/feminino, ${ }^{11}$ o público masculino sente-se incomodado com a ideia de ser objeto de um olhar ativo. Para Mulvey, a estrutura narrativa do cinema hollywoodiano, por exemplo, é uma forma de alimentar as fantasias de controle masculinas:

The male figure cannot bear the burden of sexual objectification (...). Hence the split between spectacle and narrative supports the man's role as the active one of forwarding the story, making things happen. (...) As the spectator identifies with the main male protagonist, he projects his look on to that of his like, his screen surrogate, so that the power of the male protagonist as he controls events coincides with the active power of the erotic look, both giving a satisfying sense of omnipotence. (idem: 10)

[O homem não pode suportar o fardo da objectificação sexual. (...) Por isso, a divisão entre espetáculo e narrativa concede ao personagem masculino o papel ativo para o desenvolvimento da história, impulsionando os acontecimentos. (...) À medida que o espectador se identifica com o protagonista masculino, ele projeta o seu olhar sobre o olhar do seu semelhante, seu substituto na tela, de modo a que o poder do protagonista masculino enquanto controla os acontecimentos coincida com o poder ativo do olhar erótico, ambos proporcionando uma sensação satisfatória de omnipotência].

Embora as duas faces de Corpo Verde mantenham independência formal, ${ }^{12}$ é possível ler nas imagens de Pomar a mesma desconstrução dos pressupostos patriarcais encontrada nos versos de Velho da Costa. Entretanto, se Mulvey destaca acima o modo como as 
fantasias patriarcais condicionam o funcionamento da narrativa visual, entender as imagens estáticas de Júlio Pomar exigem também ferramentas teóricas relacionadas ao campo das artes plásticas.

Nesse sentido, John Berger oferece, em seu supracitado estudo Ways of Seeing, algumas importantes reflexões. Ele observa como as pinturas a óleo europeias tendem a representar a nudez feminina por meio de personagens passivas, que, ocupado o centro da imagem, direcionam seu olhar ao espectador (Berger 1972: 52). Isso ocorre, segundo o estudioso, porque tais pinturas eram produzidas para um público masculino. É a imaginação deste público que se quer estimular por meio da ilusão de que a figura feminina enxerga esse espectador masculino como seu verdadeiro amante (idem: 56). A figura feminina, em sua nudez, não está ali para expressar alguma forma de sentimento individual (idem: 52), mas para alimentar um desejo (idem: 55).

In the average European painting of the nude the principal protagonist is never painted. He is the spectator in front of the picture and he is presumed to be a man. Everything is addressed to him. Everything must appear to be the result of his being there. It is for him that the figures have assumed their nudity. (idem: 54 )

[Em regra geral, as pinturas europeias de nu artístico nunca representam seu protagonista. Ele é o espectador em frente ao quadro, e presume-se que seja um homem. Tudo é dedicado a ele. Tudo deve parecer como resultado de ele estar ali. É por ele que as figuras assumem sua nudez].

As imagens de Júlio Pomar em Corpo Verde contrariam essa tradição. Nelas, o corpo feminino não ocupa o centro do enquadramento, nem direciona qualquer forma de olhar para o espectador. Na verdade, tanto a representação feminina como a masculina encontram-se imersas no olhar uma da outra: 


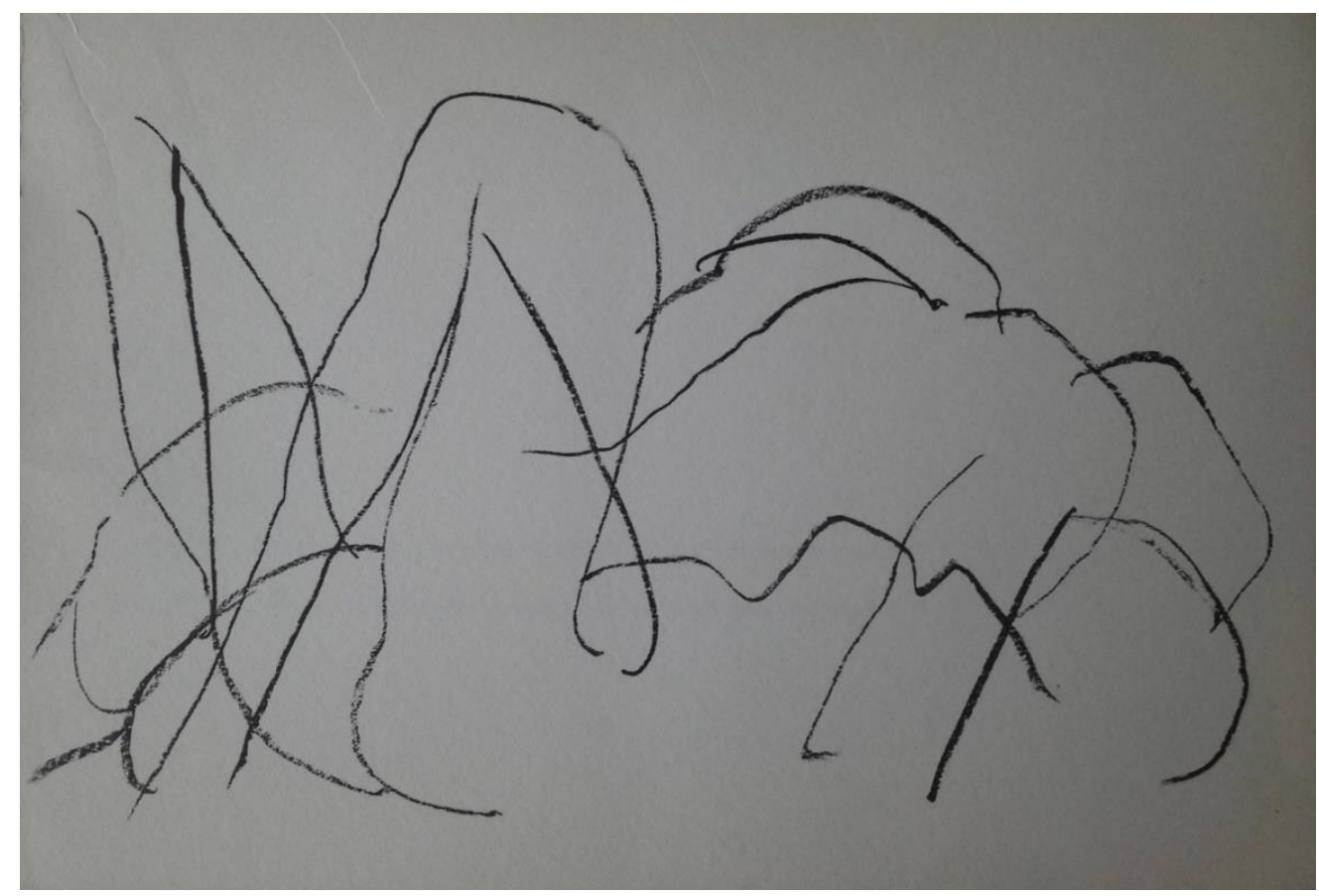

Imagem 1. (Costa/Pomar 1979: 9)

Conforme Berger, esse processo torna as figuras humanas presentes na diegese de uma imagem sujeitos, não objetos. 0 espectador masculino aqui não tem a ilusão de ser secretamente o objeto de desejo da figura feminina representada (Berger 1972: 58). Os leitores de Corpo Verde assumem a condição de intrusos, pois o que se vê é um casal na entrega contínua de um ao outro, elemento reforçado pelo fato de Pomar nunca representar a nudez dessas duas figuras em posição frontal, contrariando assim a tendência da arte erótica pós-renascentista (idem: 56).

É evidente que isso não impede o elemento basilar da representação erótica: o estímulo do desejo sexual no público observador. Porém, por nem sequer estarem cientes da presença desse público, as personagens de Pomar contrariam a redução dicotômica de atividade/passividade, conforme abordada acima por Mulvey e Berger.

Há diversos outros aspectos de composição importantes para a construção de significado, e são recorrentes nas oito imagens fornecidas: a página retangular de Corpo Verde, por exemplo, favorece a representação deitada do casal, evitando, conforme exposto acima, que uma das duas ocupe o centro do enquadramento. Não há, portanto, hierarquias 
de gênero. Quando se observam as oito imagens em sequência, as posições alternam-se. 0 conceito patriarcal de supressão é substituído pelo da mútua entrega:

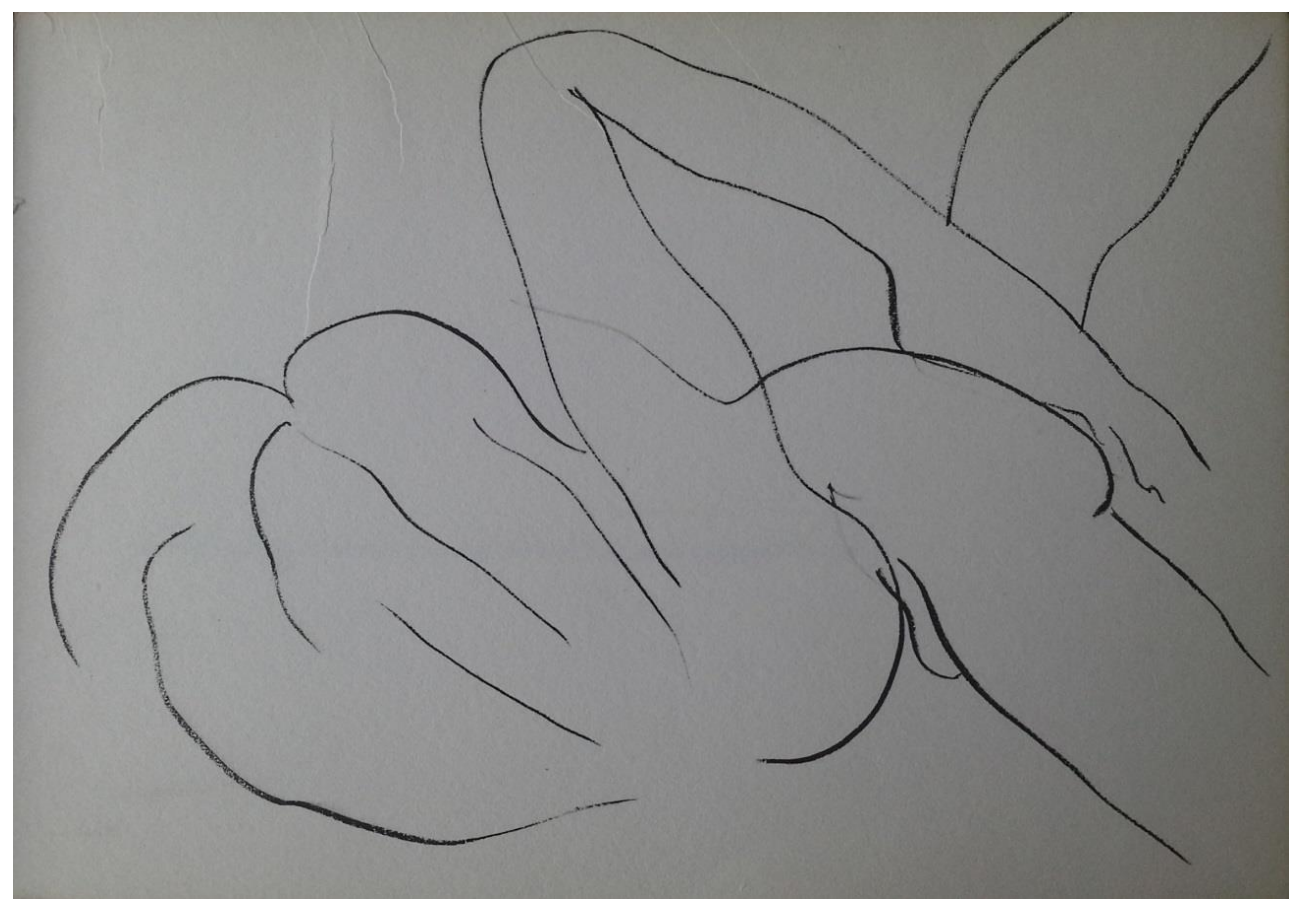

Imagem 2. (Costa/Pomar 1979: 25)

Para além dos aspectos relacionados ao enquadramento, o próprio traço de Pomar permite identificar outros paralelos entre seus desenhos e os versos de Velho da Costa. Em Corpo Verde, a arte de Pomar simula com maestria a ideia de que seus personagens são esboços, figuras em construção. 0 efeito estético derivado dessa técnica é aqui bastante rico em significados: há momentos em que as fronteiras entre dois corpos tornam-se tênues, como pode ser observado nas duas imagens acima. $\mathrm{Na}$ imagem 2, nota-se que a parte de cima dos corpos é uma única massa, mescla do casal. 0 sexo é transformado no espaço por excelência em que os limites entre o eu e o outro tornam-se nublados. É interessante observar o paralelo entre a representação visual de Pomar e a descrição da psicanalista Muriel Dimen, uma representante da corrente feminista anglo-americana: 
inner spaces, confusions about what to do next or who the other person is or what part of the body is being touched or what part of the body is doing the touching or were one person begins and the other ends. This is sometimes pleasurable, sometimes painful, always unsettling. (Dimen 1989: 46-47)

[A experiência sexual acarreta perda dos limites entre o eu e o outro, abertura sem fim de portas para espaços interiores desconhecidos, confusões sobre o que fazer a seguir, quem a outra pessoa é, qual parte do corpo está sendo tocada, qual está realizando o toque, ou onde uma pessoa começa e a outra termina. É um processo às vezes prazeroso, às vezes doloroso, sempre desconcertante].

Da mesma forma, em passagem já aqui citada, Velho da Costa escreveria: "todo amor é abolição dos limites até do próprio corpo" (Costa/Pomar 1979: 22). Os dois artistas de Corpo Verde compartilham, portanto, a primazia da fluidez sobre a rigidez identitária. Em outro dos versos da obra, lê-se: "as nossas mãos a concha, tanger do mesmo músculo submerso" (idem: 23), ou "A tua boca sobe à minha boca como uma só língua de todas as línguas"13 (idem: 27; negritos meus).

No entanto, não se propõe com isso que corpos caiam no espaço niilista da nãoidentidade. ${ }^{14}$ Afinal, na imagem de Pomar, ainda somos capazes de identificar o corpo feminino e o masculino, assim como nos versos de Velho da Costa o eu-lírico feminino permanece sempre demarcado do corpo masculino com que se deita. Na verdade, o anseio pelo mergulho temporário do eu no outro é uma forma de crescimento pessoal, pois a percepção de nossa própria individualidade expande-se quando nossos limites são explorados (Dimen 1987: 47-48). Uma das imagens de Júlio Pomar representa desta forma a tensão entre independência e correlação: 


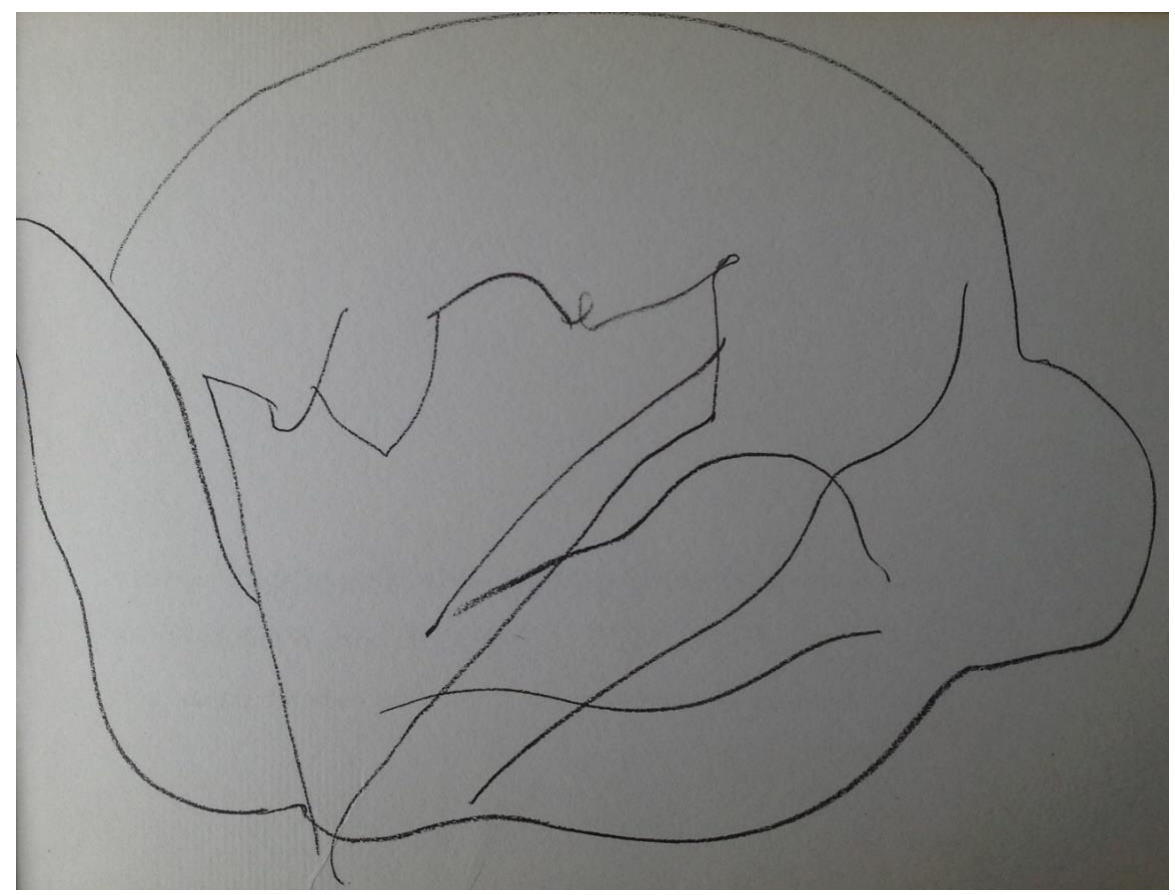

Imagem 3. (Costa/Pomar 1979: 29)

Ao reconstruírem em suas posições o símbolo japonês conhecido como yin-yang - a harmonia dos opostos, que contêm um ao outro dentro de si ao mesmo tempo que mantém suas particularidades - os corpos de Pomar realizam uma poderosa síntese do conceito de identidade fluida, de subjetividade compartilhada, que norteiam a construção de Corpo Verde em suas duas faces. Tal como no símbolo japonês, Velho da Costa e Pomar contêm o outro dentro de si ao mesmo tempo que mantêm sua independência. 0 todo estético resultante é maior do que a soma de suas partes. ${ }^{15}$ 


\section{NOTAS}

1 Muitos desses roteiros, a maioria escritos em parceria com a realizadora Margarida Gil, jamais foram publicados e poderiam, por sua vez, oferecer novas nuances sobre a escrita de Velho da Costa. Apenas Inferno, projeto para a televisão escrito com António Cabrita, foi editado em forma de livro, em tiragem reduzida, em 2001.

2 Publicada em duas versões diferentes: pela editora Dom Quixote, em 1999, e pela editor a Cotovia, em 2000, com o subtítulo "Versão de Cena". Ao comparar as duas versões, Ricardo Pais escreveria: "Na diferença entre o texto publicado pela sua editora [1999] e aquele que representamos [2000], lê-se o caminho que uma peça, escrita sobre a matéria própria da produção teatral, percorre até se legitimar com o guião de um espectáculo" (Pais 2000: 11; itálicos meus).

3 O supracitado Das Áfricas foi publicado, em edição única, em 1991.

${ }^{4}$ Serão fornecidas versões em português para as citações em língua estrangeira. Tais traduções ficam sob a responsabilidade do autor deste ensaio. Meus agradecimentos à Inês Araújo Correia pelo apoio nesta tarefa.

${ }^{5}$ As passagens do Cântico utilizadas neste ensaio foram todas extraídas da Nova Bíblia dos Capuchinhos. Para a referência completa desta edição, ver Bibliografia.

${ }^{6}$ Esta passagem da obra será retomada mais à frente a fim de expor outra questão da presente análise.

7 Chevalier e Gheerbrant também observam que o lírio pode assumir outros significados em diferentes contextos: na mitologia grega, foi associado à metamorfose (no mito de Jacinto e Apolo) e a Hades (por meio de Perséfone); nas dinastias francesas, uma representação estilizada do lírio em forma de falo associava-o à prosperidade da raça (Chevalier/Gheerbrant 1994: 413). A feminilidade deste símbolo, acima defendida, decorre de ser esta sua representação nos textos bíblicos, em geral, e no Cântico, em particular.

${ }^{8}$ Devo à Professora Camila Santos a percepção desta leitura.

${ }^{9}$ E não apenas a voz masculina, como nos primeiros capítulos do Gênesis.

${ }^{10}$ Não se tem aqui a intenção de afirmar que o texto de Velho da Costa representaria alguma forma de escrita feminina, formalmente diferente de uma suposta escrita masculina. Mais importante aqui é a divisão de gêneros relacionada à prática do olhar (gaze) e sua aceitação dentro do campo social, conforme mencionado acima em Goldhill 2007.

11 Como, ademais, o são todas as dicotomias (Darllery 1988).

${ }^{12}$ Remete-se aqui à combinação medial de Irina Rajewsky, conforme apresentada no início deste ensaio. 
13 Não se pode deixar de observar, aqui, a referência ao Milagre de Pentecostes, em "em uma só língua de todas as línguas". É o discurso religioso mais uma vez usado como matéria para a construção de imagens eróticas, não se limitando apenas ao Cântico dos Cânticos, portanto.

${ }^{14}$ Aspecto a que tanto as correntes feministas anglo-americanas (Dimen 1989: 46) como a écriture féminine se opõem (Dallery 1989: 65).

${ }^{15}$ Agradeço ao pintor Júlio Pomar a autorização para reproduzir no meu artigo os seus desenhos presentes na obra Corpo Verde. Meus agradecimentos ao Professor Doutor Rui Carvalho Homem pela leitura crítica deste ensaio. Meus agradecimentos também ao Professor Lourenço Becco pelo apoio com o processo de revisão. 


\section{Bibliografia}

Beauvoir, Simone de (2008), o Segundo Sexo, trad. Sérgio Millet, Lisboa, Quetzal Editores.

Berger, John (1972), Ways of Seeing, London, Penguin.

Bessa-Luís, Agustina (2001), “Um Tijolo Quente na Cama”, in Cântico dos Cânticos, Lisboa, Três Sinais Editores.

Bíblia Sagrada (1998), “Cântico dos Cânticos”, Português, tradução da Nova Bíblia dos Capuchinhos, coord. Herculano Alves, Lisboa, Difusora Bíblica.

Chevalier, Jean / Gheerbrant, Alain (1994), Dicionário dos Símbolos: Mitos, Sonhos, Costumes, Gestos, Formas, Figuras, Cores, Números, tradução de Cristina Rodrigues e Artur Guerra, Lisboa, Teorema.

Costa, Maria Velho da / Pomar, Júlio (1979), Corpo Verde, Lisboa, Contexto.

Dallery, Arleen B. (1989), "The Politics of Writing (the) Body: Écriture Féminine", in Gender/Body/Knowledge: Feminist Reconstructions of Being and Knowing, ed. Alison M. Jaggar and Susan R. Bordo, New Brunswick, Rutgers University Press, 2 nd paperback ed., 5267.

Dimen, Muriel (1989), "Power, Sexuality, and Intimacy", in Gender/Body/Knowledge: Feminist Reconstructions of Being and Knowing, ed. Alison M. Jaggar and Susan R. Bordo, New Brunswick, Rutgers University Press, 2nd paperback ed., 34-49.

Goldhill, Simon (2007), "What Is Ekphrasis For?" in Classical Philology, vol. 102, No.1, Special Issues on Ekphrasis, ed. by Shadi Bartsch and Jaś Elsner, Chicago, The University of Chicago Press, 1-19.

Lourenço, Frederico (2015), O Livro Aberto: Leituras da Bíblia. Lisboa, Cotovia, 2ª edição. Mitchell, W.J.T. (2005), What Do Pictures Want? The Lives and Loves of Images, Chicago, The University of Chicago Press. 
Mulvey, Laura (1975), “Visual Pleasure and Narrative Cinema”, in Screen 16-3, Oxford, 6-18. Pais, Ricardo (2000), "Mes Dames", in Madame. Porto, Ed. Cotovia/Teatro Nacional São João, 11-13.

Rajewsky, Irina 0. (2005), “Intermediality, Intertextuality, and Remediation: A Literary Perspective on Intermediality", in Intermediality: History and Theory of the Arts, Literature and Technologies, n.ำ 6, 43-64.

Daniel Floquet cresceu em Fortaleza, capital do estado do Ceará, no Brasil. Em 2007, graduou-se em Letras-Literatura pela Universidade Federal do Ceará, seguindo para a Faculdade de Letras da Universidade do Porto em 2008, onde concluiu o mestrado em Estudos Literários, Culturais e Interartes com a dissertação A Pulverização das Dicotomias em Myra, de Maria Velho da Costa. Atualmente, prepara a tese de doutoramento sobre as representações da violência nas obras de Maria Velho da Costa e Edna O’Brien, também na FLUP. Possui experiência no magistério como professor de Língua Portuguesa, assumindo as disciplinas de Literatura, Redação, Gramática e Interpretação de Texto. 